\title{
Curcumin analogue T83 exhibits potent antitumor activity and induces radiosensitivity through inactivation of Jab1 in nasopharyngeal carcinoma
}

\author{
Yunbao Pan ${ }^{1,3+}$, Mengyao Wang ${ }^{1 \dagger}$, Xianzhang Bu², Yinglin Zuo², Sumei Wang ${ }^{1}$, Dujuan Wang ${ }^{1}$, Qing Liu'
} Bojin $\mathrm{Su}^{1}$, Tao $\mathrm{Xu}^{1}$, Chunhua Wang ${ }^{1}$, Francois $X$ Claret $^{3,4^{*}}$ and Huiling Yang ${ }^{1 *}$

\begin{abstract}
Background: Nasopharyngeal carcinoma (NPC) is an Epstein-Barr virus-associated malignancy that is most common in East Asia, Africa, and Alaska. Radiotherapy is the main treatment option; unfortunately, disease response to concurrent radiotherapy and chemotherapy varies among patients with NPC, and in many cases, NPC becomes resistant to radiotherapy. Our previous studies indicated that Jab1/CSN5 was overexpressed and plays a role in the pathogenesis and radiotherapy resistance in NPC. Therefore, it is important to seek for innovative therapeutics targeting Jab1/CSN5 for NPC. In this study, we explored the antitumor effect of a curcumin analogue T83 in NPC, and found T83 exhibits antitumor activity and induces radiosensitivity through inactivation of Jab1 in NPC.

Methods: NPC cell viability and proliferation were detected by the 3-(4,5-dimethylthiazol-2-yl)-2,5diphenyltetrazolium bromide (MTT) and colony formation assays. Cell cycle distribution was detected with use of flow cytometry. Apoptosis was examined by using the Annexin V/propidium iodide staining assay and cleavage poly(ADP-ribose polymerase (PARP) and cleavage caspase-3 expression. Jab1 expression was examined by Western blotting.
\end{abstract}

Results: A growth inhibitory effect was observed with T83 treatment in a dose- and time-dependent manner. T83 significantly induced G2/M arrest and apoptosis in NPC. In addition, T83 inhibited Jab1 expression and sensitized NPC cells to radiotherapy.

Conclusion: Our data indicate that T83 exhibits potent inhibitory activity in NPC cells and induces radiotherapy sensitivity. Thus, T83 has translational potential as a chemopreventive or therapeutic agent for NPC.

Keywords: Nasopharyngeal carcinoma, Tumorigenesis, Epstein-Barr virus-associated malignancy, Jab1/CSN5, Curcumin

\section{Background}

Human nasopharyngeal carcinoma (NPC) is one of the most common cancers in Southern China [1], and the highest incidence of this disease (peaking at 50 per 100,000 persons per year) is found in this area, especially among those of Cantonese origin [2]. Epstein-Barr

\footnotetext{
* Correspondence: fxclaret@mdanderson.org; hlyangsums@hotmail.com ${ }^{\dagger}$ Equal contributors

${ }^{3}$ Department of Systems Biology, Unit 950, The University of Texas MD Anderson Cancer Center, 1515 Holcombe Blvd, Houston, TX 77030, USA 'Department of Pathophysiology, Zhongshan School of Medicine, Sun Yat-Sen University, Guangzhou, Guangdong 510080, People's Republic of China

Full list of author information is available at the end of the article
}

virus infection, environmental factors, and genetic susceptibility are all associated with NPC [3,4]. Although NPC is a relatively radiosensitive disease, the therapeutic effect of radiotherapy is not satisfactory because of radioresistance [5]. To determine the mechanism of radioresistance in this disease, our research group established the radioresistant NPC cell line (CNE2R) based on CNE2 [6]. Genetic alterations have been reported in NPC, and our recent findings showed that one such alteration, c-Jun activation domain-binding protein$1 /$ constitutive photomorphogenic-9 signalosome (Jab1/ CSN5), which negatively regulates p27, is overexpressed in this disease [7] and thus contributes to NPC resistance to

\section{Biomed Central}


radiotherapy and chemotherapy $[8,9]$. However, specific inhibitors targeting Jab1 are largely undetermined.

Curcumin is a well-known chemopreventive agent that has potent anticancer activity in a wide variety of tumor cells $[10,11]$. Unfortunately, many preclinical and clinical studies have indicated poor bioavailability and rapid metabolism of curcumin, due to its instability under certain physiologic conditions, which have limited its application in anticancer therapy [12]. Consequently, analogues of curcumin with similar safety profiles but with increased anticancer activity have been developed in recent years [11,13-15]. Interestingly, Jun $\mathrm{Li}$ et al. reported that PEGylated curcumin inhibits pancreatic cancer cell proliferation through suppression of Jab1/CSN activity [16]. Recently, our group synthesized a series of new 4-arylidene curcumin analogues that can effectively inhibit proliferation of cells in a panel of human cancer cell lines such as CNE2, SW480, MCF-7, A549, and HepG2 [17-19].

Our findings indicate that a new 4-arylidene curcumin analogue, T83, through inhibition of Jab1, exerts an antitumor effect in CNE2 and CNE2R cells by reducing cell growth, arresting the cell cycle, and increasing apoptosis. Furthermore, T83 sensitizes NPC to radiotherapy. This work identifies T83 as a potential targeted therapy that sensitizes cells prior to conventional radiotherapy, thus providing more effective treatment for NPC patients.

\section{Methods}

\section{Materials}

Cell culture reagents and fetal bovine serum (FBS) were obtained from Invitrogen (Carlsbad, CA, USA). The antibodies used were poly(ADP-ribose polymerase (PARP), p53 and p27 (BD Biosciences PharMingen, San Diego, CA, USA), caspase-3 (Cell Signaling Technology, Beverly, MA, USA), Jab1 (Santa Cruz, CA, USA), and $\beta$-actin (Sigma-Aldrich, St. Louis, MO, USA). Oligofectamine reagent was from Invitrogen, the Western Lightning Chemiluminescence Plus reagent was from Thermo Scientific Pierce (Rockford, IL, USA), MTT and DMSO were from sigma (St. Louis, MO, USA). The Annexin-V/propidium iodide (PI) kit was from BD Biosciences (Palo Alto, CA, USA). T83, which was synthesized in our laboratory, was dissolved in dimethyl sulfoxide (DMSO) to prepare a 10 $\mathrm{mM}$ stock solution and stored at $-20^{\circ} \mathrm{C}$.

\section{Synthesis of T83}

The procedure used for the synthesis of T83 was described previously [19]. Generally, an amount of $1.0 \mathrm{mmol}$ of $1,3-$ diketones curcumin analogs [20] and $2 \mathrm{mmol}$ of the corresponding benzaldehyde as well as $25 \mathrm{~mL}$ toluene were added to a three-neck rounded flask equipped with a water dispenser. Pyridine $(4.0 \mathrm{mg}, 0.05 \mathrm{mmol}$, in $0.1 \mathrm{~mL}$ toluene) and acetic acid $(4.8 \mathrm{mg}, 0.08 \mathrm{mmol}$, in $0.1 \mathrm{~mL}$ toluene) were added as catalysts. The reaction mixture was stirred in $140^{\circ} \mathrm{C}$ overnight, and the generated water was removed by water dispenser during the whole reaction. Then the reaction mixture was washed with water (10 mL, twice) to remove pyridine and acetic acid. Next the organic layer was evaporated under vacuum to get raw product. Finally the product was purified by using silica gel column chromatography.

\section{Cell lines and culture conditions}

The human NPC cell lines CNE1(well-differentiated) and CNE2 (poorly differentiated) were obtained from the Experimental Animal Center of Sun Yat-Sen University. The radioresistant NPC cell line CNE2R was generated from parental CNE2 cells as previously described [6] and identified by analysis of DNA microsatellite short tandem repeats (STR) (see additional file 1). The NPC cells were cultured in RPMI-1640 medium with 10\% FBS and antibiotics $(100 \mathrm{U} / \mathrm{mL}$ of penicillin and $100 \mu \mathrm{g} / \mathrm{mL}$ of streptomycin) in cell culture incubators at $37^{\circ} \mathrm{C}$ and aired with $5 \% \mathrm{CO}_{2}$. Cells were $\gamma$-irradiated with use of a JL Shepherd and Associates (San Fernando, CA, USA) Mark I-30 ${ }^{137} \mathrm{Cs}$ irradiator at MD Anderson Cancer Center.

\section{MTT cell viability assay}

The 3-(4,5-dimethylthiazol-2-yl)-2,5-diphenyltetrazolium bromide (MTT) assay was used to evaluate cell viability, as described previously [8]. Briefly, NPC cells were seeded in 96-well plates (2000 cells/well) in RPMI-1640 medium with $10 \%$ FBS. The following day, the cells were treated with indicated concentration of T83 or curcumin and incubated for $48 \mathrm{~h}$. A total of $20 \mu \mathrm{L}$ of MTT ( $5 \mathrm{mg} /$ $\mathrm{mL}$ ) was added to each well and incubated for $3.5 \mathrm{~h}$. The medium was discarded, and $150 \mu \mathrm{L}$ of DMSO was added to each well and incubated for $10 \mathrm{~min}$. The absorbance was read at $570 \mathrm{~nm}$. The concentration of drug required to obtain $50 \%$ maximal inhibition in cell viability was indicated by $\mathrm{IC}_{50}$.

\section{Colony formation assay}

We performed the colony formation assay as previously described [8]. Generally, the NPC cells (200 cells/well) were plated in six-well plate for growth analysis in RPMI-1640 medium with 10\% FBS. The following day, the cells were treated with indicated doses of T83. The NPC cells were grown at $37^{\circ} \mathrm{C}$ for 12 days. The effect of the drugs on growth was determined by colony growth. Colonies were stained with $0.1 \%$ crystal violet and scored by counting with an inverted microscope, using the standard definition of a colony consisting of 50 or more cells. Numbers were normalized as a percentage of colonies formed in DMSO treatment. 


\section{Measurement of cell cycle and apoptosis by flow cytometry}

The treated cells were collected and fixed overnight in $75 \%$ cold ethanol at $4^{\circ} \mathrm{C}$. Cells were then washed twice in cold phosphate-buffered saline and labeled with PI (Sigma-Aldrich), as previously described [8], and analyzed immediately after staining with use of an Epics Elite flow cytometer (Coulter Corporation, Miami, FL, USA) and WinMDI29 software.

Flow cytometric analysis, described previously [8], was used to differentiate between living, early apoptotic, late apoptotic/necrotic, and necrotic cells by staining with
Annexin V and PI. Briefly, after the indicated treatment, all of the cells were collected and resuspended in $100 \mu \mathrm{L}$ of binding buffer containing Annexin V and PI, according to the manufacturer's recommendations. Quantification of Annexin V and PI binding was performed by a FACScan flow cytometer (Becton-Dickinson).

\section{Small interfering RNA transfection}

The negative control small interfering RNA (siRNA; siControl 3) and siRNA targeting human Jab1/CSN5 (siCOPS5 \#18546) were purchased from Ambion, Inc. (Austin, TX, USA). Transient transfections of NPC cells

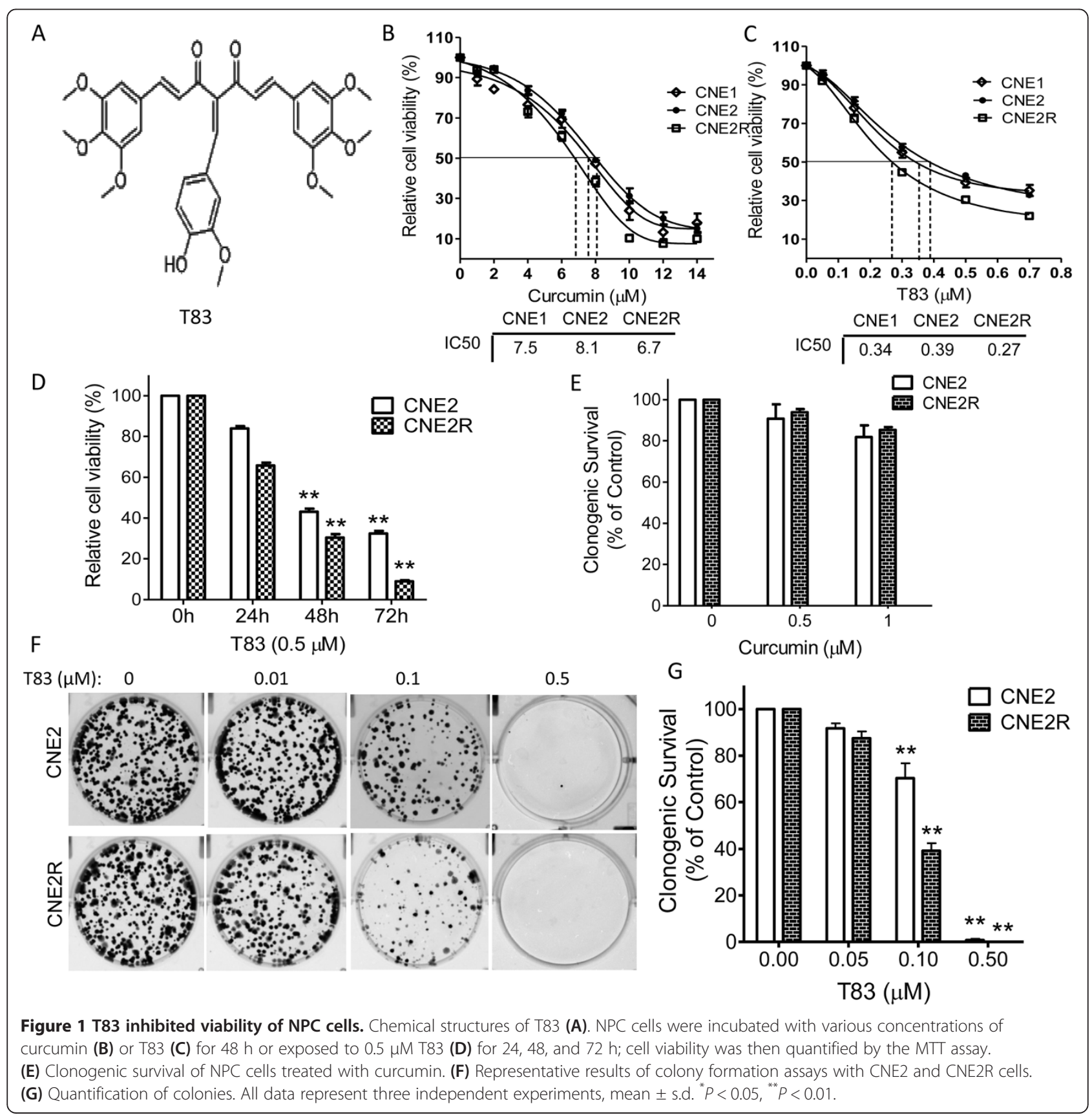


were performed as described previously [8] by using the Oligofectamine (Invitrogen) protocol with $5 \mathrm{nmol}$ siRNA in RPMI-1640 with 10\% FBS and no penicillin-streptomycin.

\section{Cell extracts and immunoblotting}

Cells in the log phase of growth were collected, washed twice in cold phosphate-buffered saline, and lysed as described previously [7]. Proteins in the total cell lysates were separated by $10 \%$ sodium dodecyl sulfate-polyacrylamide gel electrophoresis (SDS-PAGE), transferred to nitrocellulose membranes, and probed with anti-Jab1, anti-p53, anti-p27, anti-PARP, and anti-caspase-3. actin was used as the internal positive control for all immunoblots. Immunoreactive bands were detected with use of horseradish peroxidase-conjugated secondary antibodies with the Western Lightning Chemiluminescence Plus reagent. Protein levels were quantified with use of ImageJ software (National Institute of Mental Health, Bethesda, MD, USA; http://rsb.info.nih.gov/ij). Activities of PARP and caspase- 3 were measured as the proportion of cleavage band intensity to the total bands and were calculated as follows: \% PARP or caspase- $3=100 \% \times \mathrm{Tc} / \mathrm{Tt}$, where Tc is the intensity value of the cleavage bands and Tt is the intensity value of total bands.

\section{Statistical analysis}

Statistical analysis of the results was performed by using the Student's $t$ test for only two groups or by using one-
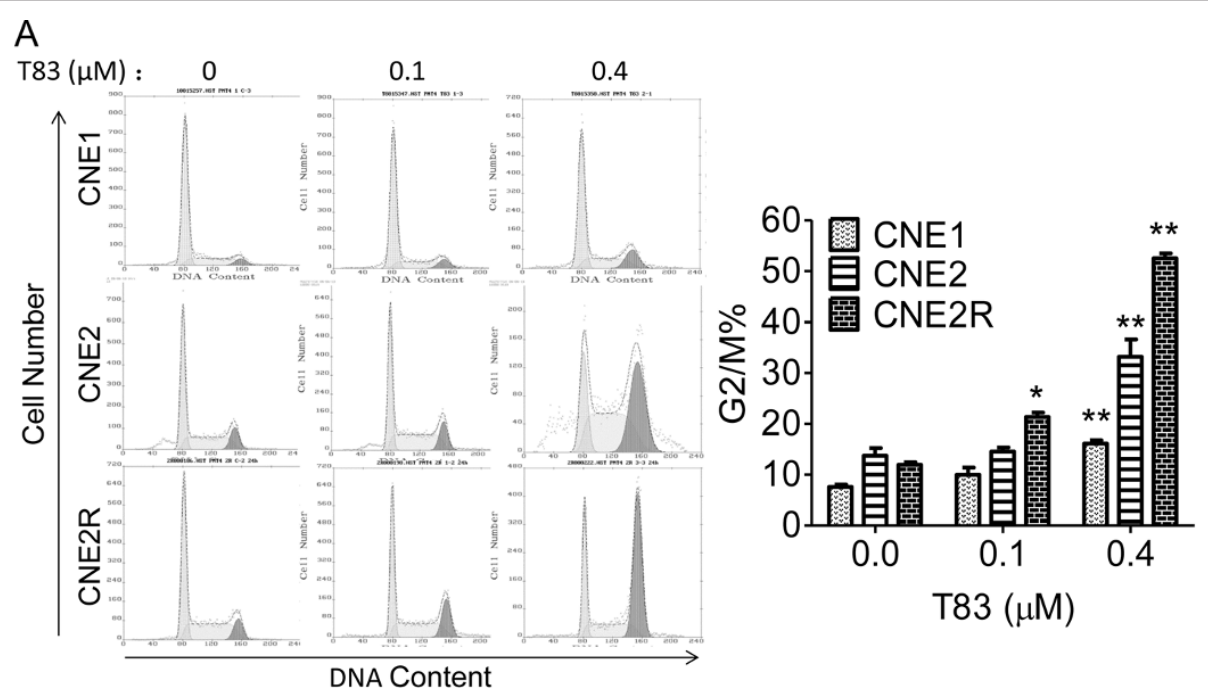

B
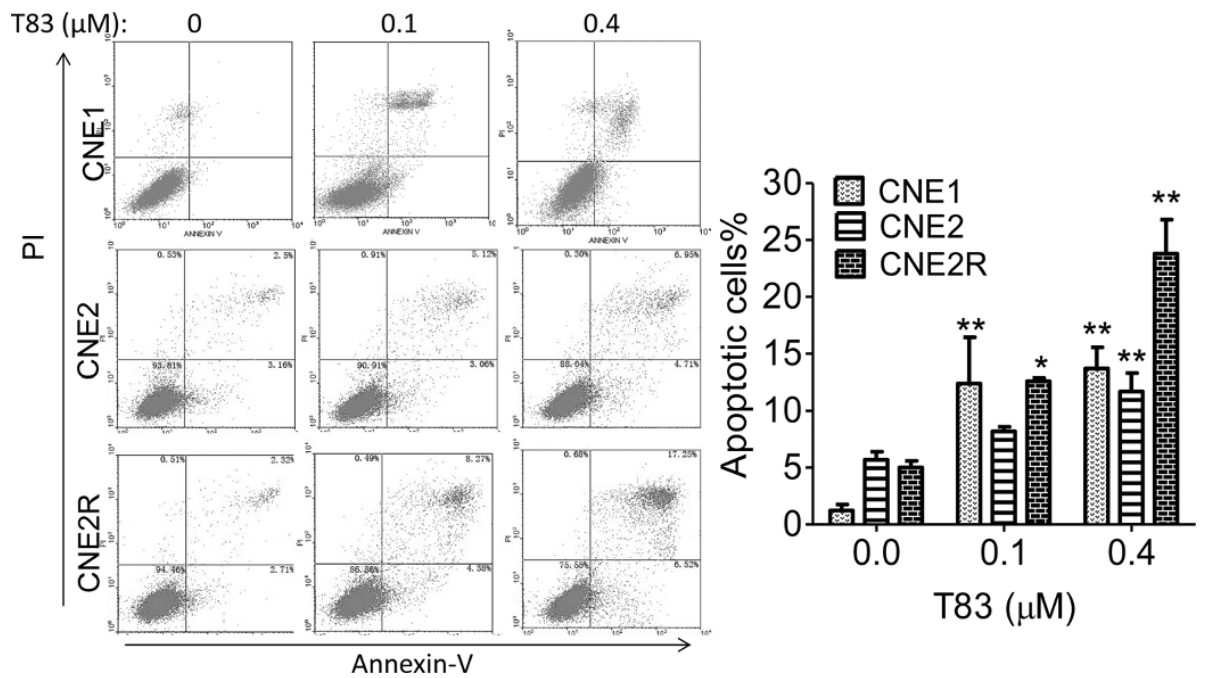

Figure 2 T83 induced cell cycle arrest and apoptosis in NPC cells. (A) The effects of T83 on cell cycle distribution in NPC cells were determined by flow cytometric analysis. Left, NPC cells were treated with DMSO control (0) or indicated concentration of T83 for $24 \mathrm{~h}$ and then fixed in ethanol and stained with propidium iodide. Right, Quantification of G2/M phase. (B) NPC cells were treated with DMSO control (0) or indicated concentration of T83 for $48 \mathrm{~h}$ and then stained with Annexin-V/PI and detected by flow cytometry. Right, Quantification of cell apoptosis. All data represent three independent experiments, mean \pm s.d. ${ }^{*} P<0.05,{ }^{* *} P<0.01$. 
way analysis of variance for more than two groups. Differences between groups were considered statistically significant at $P<0.05$. All computations were performed with SPSS 19.0 (SPSS, Chicago, IL, USA).

\section{Results}

T83 inhibited cell viability

We first examined the cytotoxicity of T83 by assessing CNE1, CNE2 and CNE2R cells. We exposed cells from NPC cell lines to various concentrations of T83. In our studies, T83 showed growth-suppressive activity in the NPC cell lines tested in a dose- and time-dependent manner (Figure 1C and 1D). However, T83 exhibited greater inhibition than curcumin. $\mathrm{IC}_{50}$ values of $\mathrm{T} 83$ were $0.34 \mu \mathrm{M}$ for CNE1, $0.39 \mu \mathrm{M}$ for CNE2 and $0.27 \mu \mathrm{M}$ for CNE2R, respectively, which are substantially more potent than curcumin $\left(\mathrm{IC}_{50}\right.$ values $7.5 \mu \mathrm{M}, 8.1 \mu \mathrm{M}$ and $\left.6.7 \mu \mathrm{M}\right)$ (Figure 1B).. In addition, we performed a colony formation assay to determine the effect of T83 on NPC cells' proliferation. As expected, T83 significantly inhibited colony formation, with more than $99 \%$ inhibition at $0.5 \mu \mathrm{M}$ treatment in the cell lines tested (Figure $1 \mathrm{~F}$ and $\mathrm{G}$ ), while the survival rated reduced only $10 \%$ (CNE2) and $7 \%$ (CNE2R) at the same concentration of curcumin treatment (Figure 1E). These results demonstrated that T83 was more potent than curcumin in inhibiting cell viability and proliferation in NPC cells.

\section{T83 induced cell cycle arrest and apoptosis in NPC}

Consistent with our observations in NPC cells, flow cytometric analysis revealed that T83 induced cell cycle arrest in CNE1 cells at the G2/M phase, with the percentage of $\mathrm{G} 2 / \mathrm{M}$ cells changing from $7.5 \%$ in DMSO-treated controls to $16.1 \%$ with $0.4 \mu \mathrm{M}$ T83 treatment for $24 \mathrm{~h}$. For the CNE2 and CNE2R cells, we got similar results: the proportion of $\mathrm{G} 2 / \mathrm{M}$ phase cells changed from $13.7 \%$ to $33.2 \%$ in CNE2 cells and from $11.9 \%$ to $52.5 \%$ in CNE2R cells (Figure $2 \mathrm{~A}$ ).

We next determined whether T83-induced cell viability inhibition is followed by increased apoptosis. NPC cells were treated with T83 for $48 \mathrm{~h}$ and analyzed by Annexin$\mathrm{V}$ and PI staining, which detects apoptosis. Treatment of NPC cells with T83 resulted in 10 times more apoptotic CNE1 cells, 2 times more CNE2 cells and 4.8 times more apoptotic CNE2R cells (Figure 2B).

Inactivation of Jab1 by T83 is dose- and time-dependent To further determine the effect of T83 on Jab1 inactivation in NPC, we exposed CNE2 and CNE2R cells to various concentrations of T83. As shown in Figure 3A and 3B, T83 inhibited Jab1 activation in a dose- and timedependent manner. As Jab1 can promote the degradation of p27 [7] and p53 [21], we further explored the effect of T83 on these two proteins. As expected, we found that the

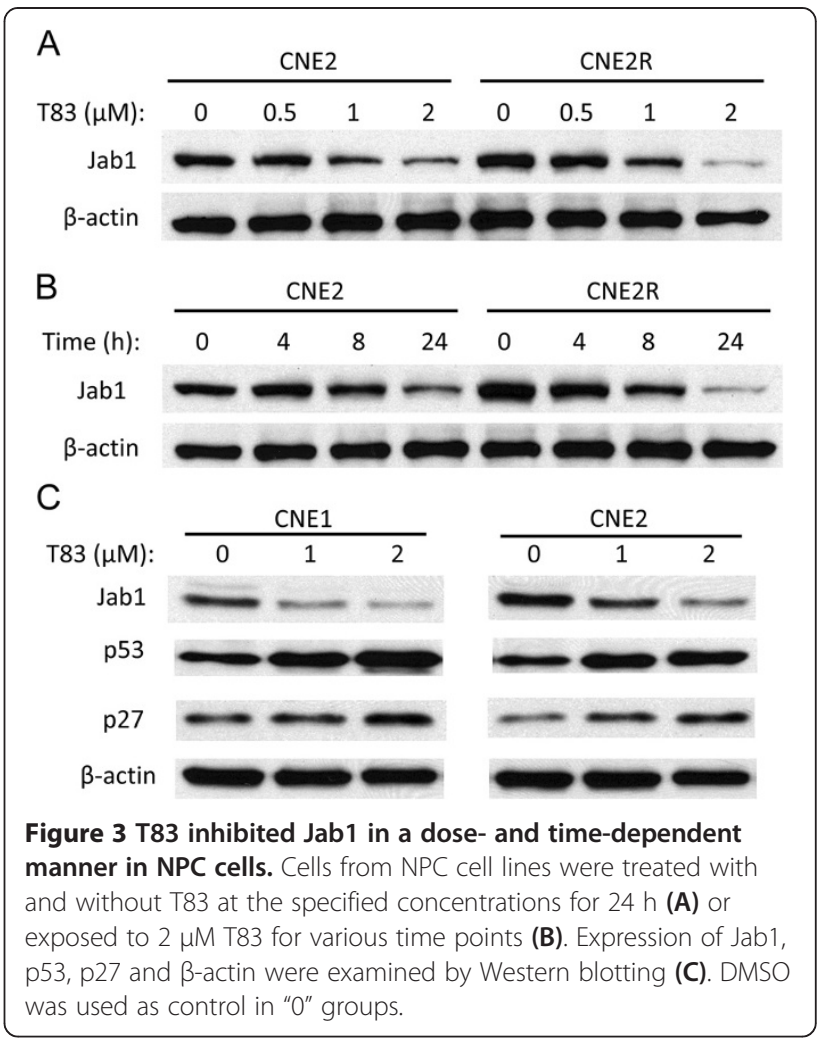

decrease of Jab1 induced by T 83 treatment was associated with an increase of p27 and p53 (Figure 3C). These data suggest that T83 inhibits Jab1 activity in NPC.

\section{Jab1 expression was associated with T83 efficacy}

To further explore the role of Jab1 in T83 action, we sought to determine whether downregulation of Jab1 would influence T83 efficacy. Thus, NPC cells were transfected with Jab1 siRNA, and cell survival was measured by the colony formation assay. Jab1 knockdown of CNE2 cells resulted in increased T83-induced cell inhibition, with $23 \%$ and $17 \%$ higher cell survival inhibition than that seen in control cells transfected with a vector at 0.05 and $0.1 \mu \mathrm{M} \mathrm{T} 83$, respectively (Figure $4 \mathrm{C}$, left). Similar results were seen in CNE2R cells transfected with Jab1 siRNA, which displayed increased T83induced cell inhibition, with $61 \%$ and $29 \%$ higher cell survival inhibition than that seen in control cells transfected with a vector at 0.05 and $0.1 \mu \mathrm{M}$ T83, respectively (Figure $4 \mathrm{C}$, right).

Consistent with the observations described above, CNE2 cells with reduced Jab1 expression showed increased efficacy of T83 ( 0.5 and $2 \mu \mathrm{M})$ compared with control cells transfected with scrambled siRNA; the hypodiploid (sub-G1) DNA content, reflecting apoptosis, was increased by $78 \%$ and $36 \%$, respectively, at these concentrations (Figure 4B, left). The CNE2R cells behaved similarly: cells in the sub-G1 phase increased by 

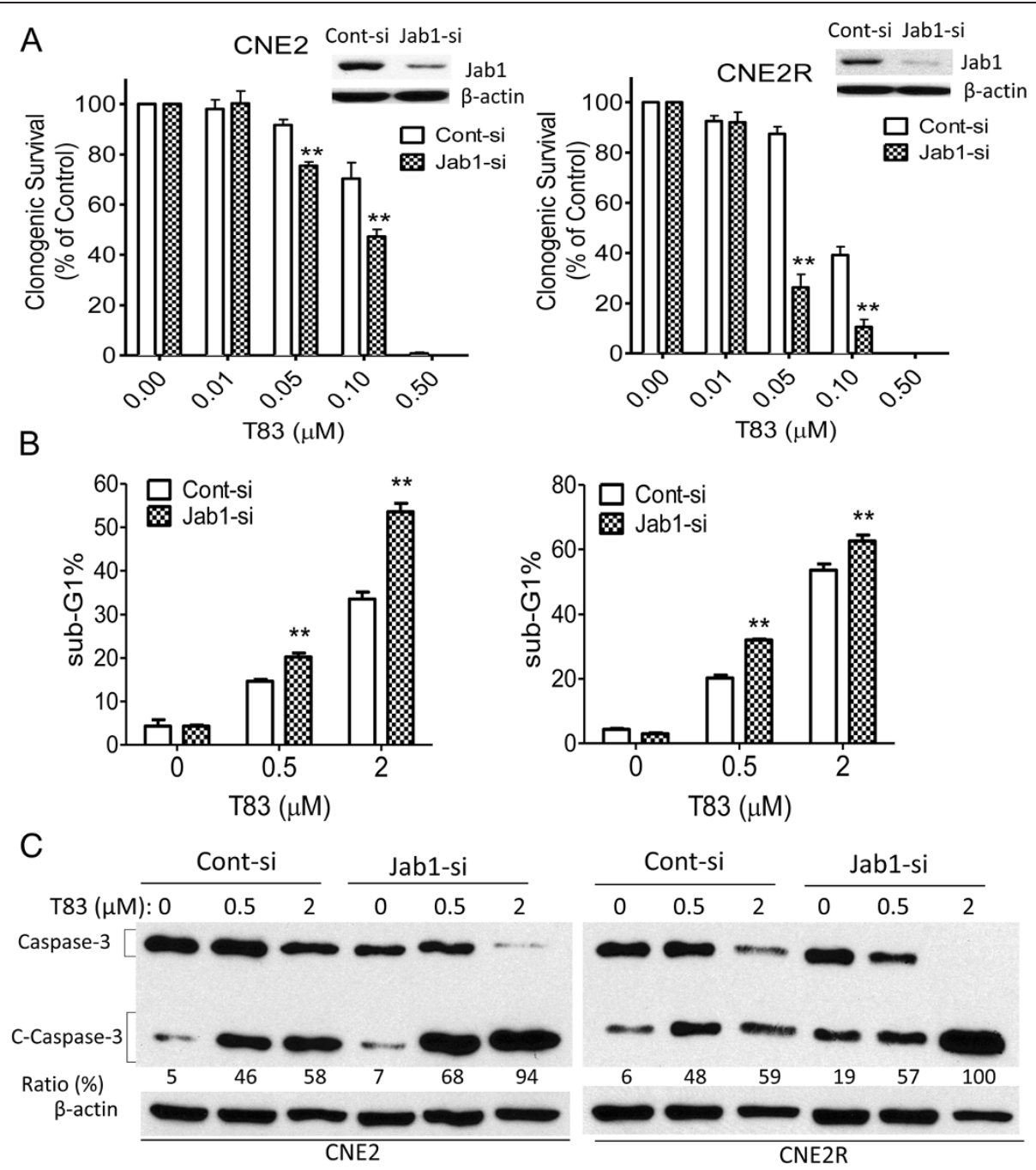

Figure 4 Jab1 knockdown enhanced the effects of T83 on cell viability inhibition and apoptosis induction. CNE2 cells (left) and CNE2R cells (right) were transfected with control siRNA (Cont-si) or Jab1 siRNA (Jab1-si) and then exposed to the indicated doses of T83 for 48 h; they were then examined for colony formation (A), sub-G1 (B), and cleaved caspase-3 (C-Caspase 3) (C). Protein levels were quantified with use of ImageJ software. All data represent three independent experiments, mean \pm s.d. DMSO was used as control in "0" groups.

$60 \%$ and $19 \%$, respectively (Figure $4 \mathrm{~B}$, right) at the above concentrations of T83. Similar results were seen when we tested caspase-3 cleavage. CNE2 cells (Figure 4C, left) and CNE2R cells (Figure 4C, right) transfected with Jab1 siRNA displayed increased T83-induced caspase-3 cleavage compared with control cells. Considering our findings together, we conclude that Jab1 levels were associated with T83 efficacy.

\section{T83 sensitizes NPC cells to radiotherapy}

Because radiotherapy is the main treatment for NPC, we investigated whether T83 is involved in the antitumor effects of radiotherapy. We first used the colony formation assay to verify the effects of radiotherapy on CNE2 and CNE2R cells. We observed results similar to those previously reported [6], that $\mathrm{CNE} 2 \mathrm{R}$ cells are more resistant to irradiation (IR) (Figure 4A). We next used a suboptimal dose $\left(\leq \mathrm{IC}_{10}\right)$ of $\mathrm{T} 83$ to examine whether T83 increased the sensitivity of NPC cells to IR. As expected, NPC cells treated with T83 showed increased sensitivity to IR compared with control cells treated with IR alone. The survival rates of CNE2 cells treated with T83 were reduced by $20 \%$ and $44 \%$ when exposed to 4 and 8 Gy of radiation, respectively (Figure $5 \mathrm{~B}$ ), whereas survival rates of CNE2R cells treated with T83 were reduced by $47 \%$ and $57 \%$, respectively, at these exposures (Figure 5C).

We further examined whether T83 could enhance IRinduced apoptosis in NPC cells. We found that IR treatment increased apoptosis in T83-treated cells more than in control cells, i.e., by $70 \%$ in CNE2 cells and by $140 \%$ in CNE2R cells, as measured by PI staining (Figure 5D). Proteolytic cleavage of PARP and cleaved caspase- 3 are 


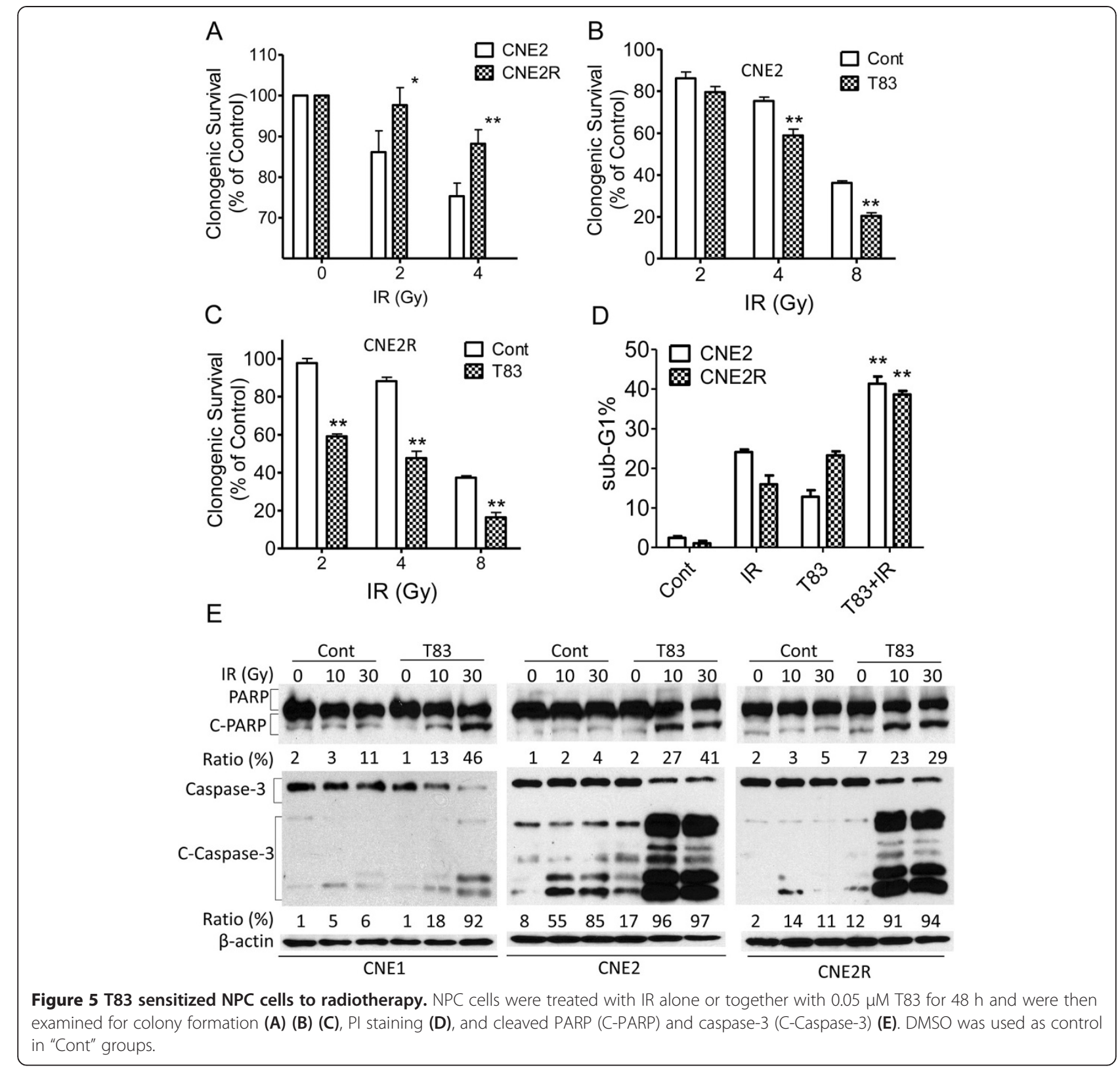

the hallmarks of apoptosis [22,23]. Thus, we also examined the effects of T83 on the proteolytic cleavage of PARP and cleaved caspase- 3 in response to IR. Compared with results for the control cells, IR consistently induced more proteolytic cleavage of PARP (35\% change in CNE1, 37\% change in CNE2 cells, 24\% change in CNE2R cells) and cleaved caspase-3 (86\% change in CNE1, 41\% change in CNE2 cells, 83\% change in CNE2R cells) in T83-treated cells (Figure 5D).

\section{Discussion}

In the current study, we have presented evidence showing the effective inhibition of Jab1 by the new 4-arylidene curcumin analogue, T83, which resulted in antitumor effects in NPC cells. These findings suggest that T83 may be effective in suppressing NPC cell growth in patients with cancer.

We first confirmed that a synthetic analogue of curcumin, T83, could significantly inhibit cell proliferation in NPC cells. T83 is highly effective in inhibiting cell viability and clone formation in NPC cell lines, and its $\mathrm{IC}_{50}$ value is much lower than the $\mathrm{IC}_{50}$ values of other curcumin analogues [17]. Furthermore, we have shown that T83 can arrest the cell cycle at the G2/M phase and induce apoptosis in a dose-dependent manner. Previous studies had shown that cells in the G2/M phase are the most sensitive to radiation and that tumor cells in this phase are the most responsive to IR and 
chemotherapy $[24,25]$. In our study, the number of radioresistant CNE2R cells in the G2/M phase increased significantly in a dose-dependent way. All of these data supported T83's effect on reversing radioresistance by increasing $\mathrm{G} 2 / \mathrm{M}$ phase accumulation.

Because Jab1 is overexpressed in many cancers including NPC [7], suppression of Jab1 contributes to the sensitivity of cisplatin chemotherapy and radiotherapy [8]. Inhibiting the Jab1 signaling pathway may be an effective strategy in the treatment of NPC, and we here presented the first evidence of T83 activity in NPC. We also found that T83 is effective in inhibiting Jab1 expression in a dose- and time-dependent manner. Given these findings, we examined the potential effects of Jab1 on T83's activity in NPC. Knockdown of Jab1 enhanced T83's activity against NPC cells.

Interestingly, all of our experiments showed that radiation-resistant cells (CNE2R) are more sensitive to T83 than the parental CNE2 cells; we therefore speculated that T83 possibly sensitizes NPC cells to radiotherapy. To test this hypothesis, we selected a suboptimal dose $\left(\leq \mathrm{IC}_{10}\right)$ of $\mathrm{T} 83$ to examine whether T83 increased the sensitivity of NPC cells to IR. Our study suggested that T83 treatment in combination with radiotherapy improve the response of NPC to radiotherapy.

\section{Conclusions}

Taken together, our results indicated that T83 exhibits enhanced antitumor activity in NPC cells. Our findings, which demonstrated that T83 inhibited Jab1 and supported T83 as an anticancer agent, could have important clinical relevance, namely, that administration of T83 could become part of an effective therapeutic regimen for NPC.

\section{Additional file}

Additional file 1: STR profiling of CNE2 and CNE2R.

\begin{abstract}
Abbreviations
DMSO: Dimethyl sulfoxide; FBS: Fetal bovine serum; $I C_{50}$ : Concentration of drug required to obtain 50\% maximal inhibition in cell viability; IR: Ionizing radiation; MTT: 3-(4,5-dimethylthiazol-2-yl)-2,5-diphenyltetrazolium bromide; NPC: Nasopharyngeal carcinoma; PI: Propidium iodide; siRNA: small interfering RNA.
\end{abstract}

\section{Competing interests}

The authors declare that they have no competing interests.

\section{Authors' contributions}

YP conceived of the study, designed and performed the experiments, analyzed data and drafted the manuscript. MW designed and performed the experiments. $X B$ and $Y Z$ contributed reagents and performed experiments. SW, DW, QL, BS, TX and CW performed experiments. FXC and HY conceived of the study, and participated in its coordination and helped to draft the manuscript. All authors read and approved the final manuscript.
Authors' information

Yunbao Pan and Mengyao Wang co-first author.

\section{Acknowledgements}

This work was supported by a fellowship from the China Scholarship Council (2010638087) (YP); the National Natural Science Foundation of China (81071837; 30670627); the Foundation of Guangdong Province, China (9251008901000005; 06021210); the Scientific and Technological Project of Guangdong, China (2008A030201009; 2010B050700016) (HY); the National Natural Science Foundation of China (81172931; 30973619) (XB); and a grant from the National Cancer Institute (R01-CA90853) (FXC).This research is supported in part by the National Institutes of Health through MD Anderson's Cancer Center Support Grant CA016672.

\section{Author details}

'Department of Pathophysiology, Zhongshan School of Medicine, Sun YatSen University, Guangzhou, Guangdong 510080, People's Republic of China. 2Department of Microbial and Biochemical Pharmacy, School of Pharmaceutical Sciences, Sun Yat-sen University, Guangzhou 510006, People's Republic of China. ${ }^{3}$ Department of Systems Biology, Unit 950, The University of Texas MD Anderson Cancer Center, 1515 Holcombe Blvd, Houston, TX 77030, USA. ${ }^{4}$ Experimental Therapeutic Academic Program and Cancer Biology Program, The University of Texas Graduate School of Biomedical Sciences at Houston, 6767 Bertner Ave, Houston, TX 77030, USA.

Received: 28 January 2013 Accepted: 20 June 2013

Published: 1 July 2013

\section{References}

1. Lo KW, Chung GT, To KF: Deciphering the molecular genetic basis of NPC through molecular, cytogenetic, and epigenetic approaches. Semin Cancer Biol 2012, 22(2):79-86.

2. Spano JP, Busson P, Atlan D, Bourhis J, Pignon JP, Esteban C, Armand JP: Nasopharyngeal carcinomas: an update. Eur J Cancer 2003, 39(15):2121-2135

3. Lo KW, To KF, Huang DP: Focus on nasopharyngeal carcinoma. Cancer Cell 2004, 5(5):423-428.

4. Wei WI, Sham JS: Nasopharyngeal carcinoma. Lancet 2005, 365(9476):2041-2054.

5. Yip KW, Mocanu JD, Au PY, Sleep GT, Huang D, Busson P, Yeh WC, Gilbert R, O'Sullivan B, Gullane $P$, et al: Combination bcl-2 antisense and radiation therapy for nasopharyngeal cancer. Clin Cancer Res 2005, 11(22):8131-8144.

6. Qu C, Liang Z, Huang J, Zhao R, Su C, Wang S, Wang X, Zhang R, Lee MH, Yang $\mathrm{H}$ : MiR-205 determines the radioresistance of human nasopharyngeal carcinoma by directly targeting PTEN. Cell Cycle 2012, 11(4):785-796.

7. Pan Y, Zhang Q, Tian L, Wang X, Fan X, Zhang H, Claret FX, Yang H: Jab1/ CSN5 negatively regulates p27 and plays a role in the pathogenesis of nasopharyngeal carcinoma. Cancer Res 2012, 72(7):1890-1900.

8. Pan Y, Zhang Q, Atsaves V, Yang H, Claret FX: Suppression of Jab1/CSN5 induces radio- and chemo-sensitivity in nasopharyngeal carcinoma through changes to the DNA damage and repair pathways. Oncogene 2013, 32(22):2756-2766.

9. Pan Y, Claret FX: Targeting Jab1/CSN5 in nasopharyngeal carcinoma. Cancer Lett 2012, 326(2):155-160.

10. Ji JL, Huang XF, Zhu HL: Curcumin and its formulations: potential anticancer agents. Anticancer Agents Med Chem 2012, 12(3):210-218.

11. Yogosawa S, Yamada Y, Yasuda S, Sun Q, Takizawa K, Sakai T: Dehydrozingerone, a Structural Analogue of Curcumin, Induces CellCycle Arrest at the G2/M Phase and Accumulates Intracellular ROS in HT29 Human Colon Cancer Cells. J Nat Prod 2012, 75(12):2088-2093.

12. Anand P, Kunnumakkara AB, Newman RA, Aggarwal BB: Bioavailability of curcumin: problems and promises. Mol Pharm 2007, 4(6):807-818.

13. Cen L, Hutzen B, Ball S, DeAngelis S, Chen CL, Fuchs JR, Li C, Li PK, Lin J: New structural analogues of curcumin exhibit potent growth suppressive activity in human colorectal carcinoma cells. BMC Cancer 2009, 9:99.

14. Debata PR, Castellanos MR, Fata JE, Baggett S, Rajupet S, Szerszen A, Begum S, Mata A, Murty W, Opitz LM, et al: A novel curcumin-based vaginal cream Vacurin selectively eliminates apposed human cervical cancer 
cells. Gynecol Oncol 2012:0090-8258. (0012)00952-00953 [pii]/00910.01016/j. ygyno.02012.00912.00005.

15. Manohar S, Khan SI, Kandi SK, Raj K, Sun G, Yang X, Calderon Molina AD, Ni $\mathrm{N}$, Wang B, Rawat DS: Synthesis, antimalarial activity and cytotoxic potential of new monocarbonyl analogues of curcumin. Bioorg Med Chem Lett 2013, 23(1):112-116.

16. Li J, Wang Y, Yang C, Wang P, Oelschlager DK, Zheng Y, Tian DA, Grizzle WE, Buchsbaum DJ, Wan M: Polyethylene glycosylated curcumin conjugate inhibits pancreatic cancer cell growth through inactivation of Jab1. Mol Pharmacol 2009, 76(1):81-90.

17. Zuo Y, Huang J, Zhou B, Wang S, Shao W, Zhu C, Lin L, Wen G, Wang H, Du $J$, et al: Synthesis, cytotoxicity of new 4-arylidene curcumin analogues and their multi-functions in inhibition of both NF-kappaB and Akt signalling. Eur J Med Chem 2012, 55:346-357.

18. Liu H, Zhou BH, Qiu X, Wang HS, Zhang F, Fang R, Wang XF, Cai SH, Du J, Bu XZ: T63, a new 4-arylidene curcumin analogue, induces cell cycle arrest and apoptosis through activation of the reactive oxygen speciesFOXO3a pathway in lung cancer cells. Free Radic Biol Med 2012, 53(12):2204-2217.

19. Qiu X, Du Y, Lou B, Zuo Y, Shao W, Huo Y, Huang J, Yu Y, Zhou B, Du J, et al: Synthesis and Identification of New 4-Arylidene Curcumin Analogues as Potential Anticancer Agents Targeting Nuclear FactorkappaB Signaling Pathway. J Med Chem 2010, 53(23):8260-8273.

20. Qiu X, Liu Z, Shao WY, Liu X, Jing DP, Yu YJ, An LK, Huang SL, Bu XZ, Huang $\mathrm{ZS}$, et al: Synthesis and evaluation of curcumin analogues as potential thioredoxin reductase inhibitors. Bioorg Med Chem 2008, 16(17):8035-8041.

21. Zhang XC, Chen J, Su CH, Yang HY, Lee MH: Roles for CSN5 in control of p53/MDM2 activities. J Cell Biochem 2008, 103(4):1219-1230.

22. Lazebnik YA, Kaufmann SH, Desnoyers S, Poirier GG, Earnshaw WC Cleavage of poly(ADP-ribose) polymerase by a proteinase with properties like ICE. Nature 1994, 371(6495):346-347.

23. Nicholson DW, Ali A, Thornberry NA, Vaillancourt JP, Ding CK, Gallant M, Gareau Y, Griffin PR, Labelle M, Lazebnik YA, et al: Identification and inhibition of the ICE/CED-3 protease necessary for mammalian apoptosis. Nature 1995, 376(6535):37-43.

24. Krueger SA, Wilson GD, Piasentin E, Joiner MC, Marples B: The effects of G2phase enrichment and checkpoint abrogation on low-dose hyperradiosensitivity. Int J Radiat Oncol Biol Phys 2010, 77(5):1509-1517.

25. Fernet M, Megnin-Chanet F, Hall J, Favaudon V: Control of the G2/M checkpoints after exposure to low doses of ionising radiation: implications for hyper-radiosensitivity. DNA Repair (Amst) 2010, 9(1):48-57.

doi:10.1186/1471-2407-13-323

Cite this article as: Pan et al:: Curcumin analogue T83 exhibits potent antitumor activity and induces radiosensitivity through inactivation of Jab1 in nasopharyngeal carcinoma. BMC Cancer 2013 13:323.

\section{Submit your next manuscript to BioMed Central and take full advantage of:}

- Convenient online submission

- Thorough peer review

- No space constraints or color figure charges

- Immediate publication on acceptance

- Inclusion in PubMed, CAS, Scopus and Google Scholar

- Research which is freely available for redistribution 